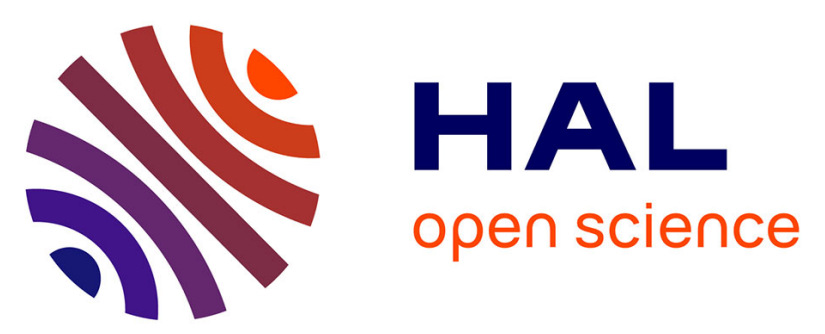

\title{
Morphometry of Middle Bronze Age palstaves. Part II - spatial distribution of shapes in two typological groups, implications for production and exportation.
}

Fabrice Monna, Ahmad Jebrane, Maréva Gabillot, Rémi Laffont, Marie

Specht, Benjamin Bohard, Estelle Camizuli, Christophe Petit, Carmela

Chateau, Paul Alibert

\section{To cite this version:}

Fabrice Monna, Ahmad Jebrane, Maréva Gabillot, Rémi Laffont, Marie Specht, et al.. Morphometry of Middle Bronze Age palstaves. Part II - spatial distribution of shapes in two typological groups, implications for production and exportation.. Journal of Archaeological Science, 2013, 40 (1), pp.507516. 10.1016/j.jas.2012.06.029 . hal-00748207

\section{HAL Id: hal-00748207 \\ https://hal.science/hal-00748207}

Submitted on 4 May 2020

HAL is a multi-disciplinary open access archive for the deposit and dissemination of scientific research documents, whether they are published or not. The documents may come from teaching and research institutions in France or abroad, or from public or private research centers.
L'archive ouverte pluridisciplinaire HAL, est destinée au dépôt et à la diffusion de documents scientifiques de niveau recherche, publiés ou non, émanant des établissements d'enseignement et de recherche français ou étrangers, des laboratoires publics ou privés. 


\title{
Morphometry of Middle Bronze Age palstaves. Part II - spatial distribution of shapes in two typological groups, implications for production and exportation
}

\author{
F. Monna ${ }^{\mathrm{a}, *}$, A. Jebrane ${ }^{\mathrm{b}}$, M. Gabillot ${ }^{\mathrm{a}}$, R. Laffont ${ }^{\mathrm{c}}$, M. Specht ${ }^{\mathrm{a}}$, B. Bohard ${ }^{\mathrm{a}}$, E. Camizuli ${ }^{\mathrm{a}}$, C. Petit $^{\mathrm{d}}$, \\ C. Chateau ${ }^{\mathrm{e}}$, P. Alibert ${ }^{\mathrm{c}}$ \\ ${ }^{a}$ ARTeHIS, UMR 6298, Université de Bourgogne, CNRS, 6 Bd Gabriel, bât. Sciences Gabriel, F-21000 Dijon, France \\ ${ }^{\mathrm{b}}$ IMB, UMR 5584, Université de Bourgogne, CNRS, 6 Bd Gabriel, bât. Sciences Mirande, F-21000 Dijon, France \\ ${ }^{\mathrm{c}}$ Biogéosciences, UMR 6282, Université de Bourgogne, CNRS, 6 Bd Gabriel, bât. Sciences Gabriel, F-21000 Dijon, France \\ ${ }^{\mathrm{d}}$ ARSCAN UMR 7041, Equipe "Archéologie environnementales», Université de Paris 1, 3 rue Michelet, F-75006 Paris, France \\ e UFR SVTE, Université de Bourgogne, 6 Bd Gabriel, bât. Sciences Gabriel, F-21000 Dijon, France
}

\section{A R T I C L E I N F O}

\section{Article history:}

Received 17 March 2012

Received in revised form

6 June 2012

Accepted 7 June 2012

\section{Keywords:}

Morphometrics

Axe

Shape analysis

Open contour

Archaeology

Orthogonal polynomials

Typology

\begin{abstract}
A B S T R A C T
For archaeologists, metallic artifacts are key materials to assess Middle Bronze Age production areas and cultural exchanges. Here, a set of 629 bronze palstaves excavated in northern France, belonging to Breton and Norman typological groups, was treated by (open) outline-based morphometrics with orthogonal polynomial regression. Using robust statistics developed for outlier detection, these Norman and Breton palstave outlines can be divided into two groups: those for which the shape fluctuates close to the standard shape, called "congruent" axes, and those which are far enough from this standard to be considered as "non-congruent", although they possess most of the features of the typological group. The highest density of discovery (whether congruent and non-congruent in shape) is in the extreme east of Brittany for the Breton axes, while the Norman axes are concentrated in northern Normandy, hence the choice of names. However, the distribution of congruent and non-congruent artifacts appears to be spatially dependent for the Norman group, and to a lesser extent for the Breton group, as there are proportionally more congruent specimens inside the supposed production areas than outside. This contradicts the generally accepted archaeological scheme which hypothesizes that all axes in a group originate from the same production center, and that some items were exported from there to supply neighboring regions. Other minor production centers probably existed, copying the original model with greater shape variation.
\end{abstract}

(C)

\section{Introduction}

In Western Europe, the Middle Bronze Age (1650-1350 BC) was a period where production of metallic objects developed (Briard, 1965; Rowlands, 1976; O'Connor, 1980; Briard and Bigot, 1989). In France, bronze palstave blades are particularly well represented (Verney, 1989; Gabillot, 2003). Such abundance is probably linked to the need for tools to clear forests for agricultural purposes and also in response to the increasing demand for wood. Several types of palstave blades have been recognized by archaeologists of the French Prehistorical Society (Briard and Verron, 1976). Their classification is based on macroscopic observations, including the general shape and the presence of specific ornaments. Two types are particularly abundant in northern France: the Breton and the

\footnotetext{
* Corresponding author. Tel.: +33 (0)3 803963 60; fax: +33 (0)3 80395787 E-mail address: Fabrice.Monna@u-bourgogne.fr (F. Monna).
}

Norman types, named after their areas of highest discovery density, the Breton peninsula and Normandy (Briard, 1965; Verney, 1989, recently confirmed by Gabillot, 2003). The numerous specimens found several hundred kilometers away from their supposed production areas are commonly interpreted as resulting from export. Although very useful, the assignment of artifacts to a particular type supplies no information about morphological distribution inside the type, in terms of mean shape and shape diversity (disparity). The close examination by morphometric procedures of the population forming a type may, however, provide finer clues about production areas, possible diffusion of artifacts, know-how, and population mobility.

In a recent companion work, it was demonstrated that the open outline of the inner lateral rib was a powerful morphometric criterion to discriminate Breton and Norman specimens as it separated the two populations in a similar way to traditional typology based on macroscopic observations (Forel et al., 2009). The choice of the inner lateral rib ensues from the fact that the rib is 
more regular than the lateral curvature as it is representative of the mold, and that its shape is not drastically modified by elimination of the casting cone, preparation of the axe for use, or further repetitive sharpening operations (Gabillot, 2006). Axe profiles were treated by Discrete Cosine Transform (DCT), a procedure already applied in paleontology to study ammonite species (Dommergues et al., 2006, 2007), followed by a discriminant analysis performed on computed harmonic amplitudes. Special attention was paid to possible sources of error, such as obtaining the inner lateral rib from archaeological documentation, the drawing operation itself, and the mathematical treatments (these steps are detailed in Forel et al., 2009). It is noteworthy that considering the inner lateral rib as the sole descriptor of blades is a reductionist approach, as other useful parameters featuring the axes are now ignored (e.g. presence and nature of decorations, metal composition, etc). However, by extracting only a few coefficients representative of the shape, it becomes possible to quantify shape disparity within each group precisely and to calculate the distance separating a particular item from the mean shape of its typological group. This valuable information is inaccessible to the naked eye. In the previous study, Breton palstaves appeared to be significantly more standardized than Norman ones, suggesting regional differences in the organization of metallic production (Forel et al., 2009). Interestingly, most of the palstaves discovered at Sermizelles (Burgundy), a site located several hundred kilometers from Brittany and Normandy (lower Seine Valley), were far from the standard shapes featuring the Norman and Breton types. They did not define a third typological group either, as they displayed a vast variety of shapes with many individuals, spreading out to the edge of the morphological space of Breton and Norman axes, or even outside (see Forel et al., 2009, Fig. 5c, p. 726). Their shape disparity was therefore too great to be compatible with a simple assortment of Breton and Norman types, as previously believed. Some of them therefore possibly came from other sources, perhaps from copies, as they presented most of the features commonly found in both Breton and Norman types (Forel et al., 2009; Gabillot et al., 2009). The concluding remark of this previous work was that other centers of Norman- and Breton-like palstaves may have existed outside the presumed limits of production areas. Strong presumptions plead in favor of local production in the region of Sermizelles, where environmental studies have indicated that nearby mineral resources were exploited by Prehistoric societies (Monna et al., 2004; JouffroyBapicot et al., 2007). However, the morphological data from this previous set of axes were not treated by spatial analysis, because the main focus of the study was the comparison of axes found in or nearby the presumed production areas (Brittany and Normandy), with axes from the Sermizelles hoard.

Classically, the geographical distribution of artifacts may reveal places where major production took place (perhaps even secondary, minor centers). Our working hypothesis is that links may exist between spatial distribution and artifact shape. We therefore sought to identify geographical clusters of high or low proportions of specimens presenting features close to the mean shape. If such clusters can be recognized, the spatial distribution of artifacts can therefore be aligned with natural, social and cultural phenomena. Characterizing these links may be of great value in understanding the organization of production, and hence, in assessing the material and immaterial relationships linking prehistoric societies.

\section{Material and method}

\subsection{Corpus}

Data were acquired on an extended corpus compared to the previous study: 319 palstaves of Breton type instead of 203, and 310 Norman ones instead of 177 (see Fig. 1 for main characteristics of Norman and Breton palstaves). This new corpus now covers a wider geographical area (74 locations for the Breton and 98 for the Norman types), which extends far beyond the presumed production districts (i.e. Brittany and Normandy), as it encompasses approximately the northern half of the current French territory (Fig. 2). The aim, here, is to compare districts assumed to be sites of active production, and neighboring regions which are classically

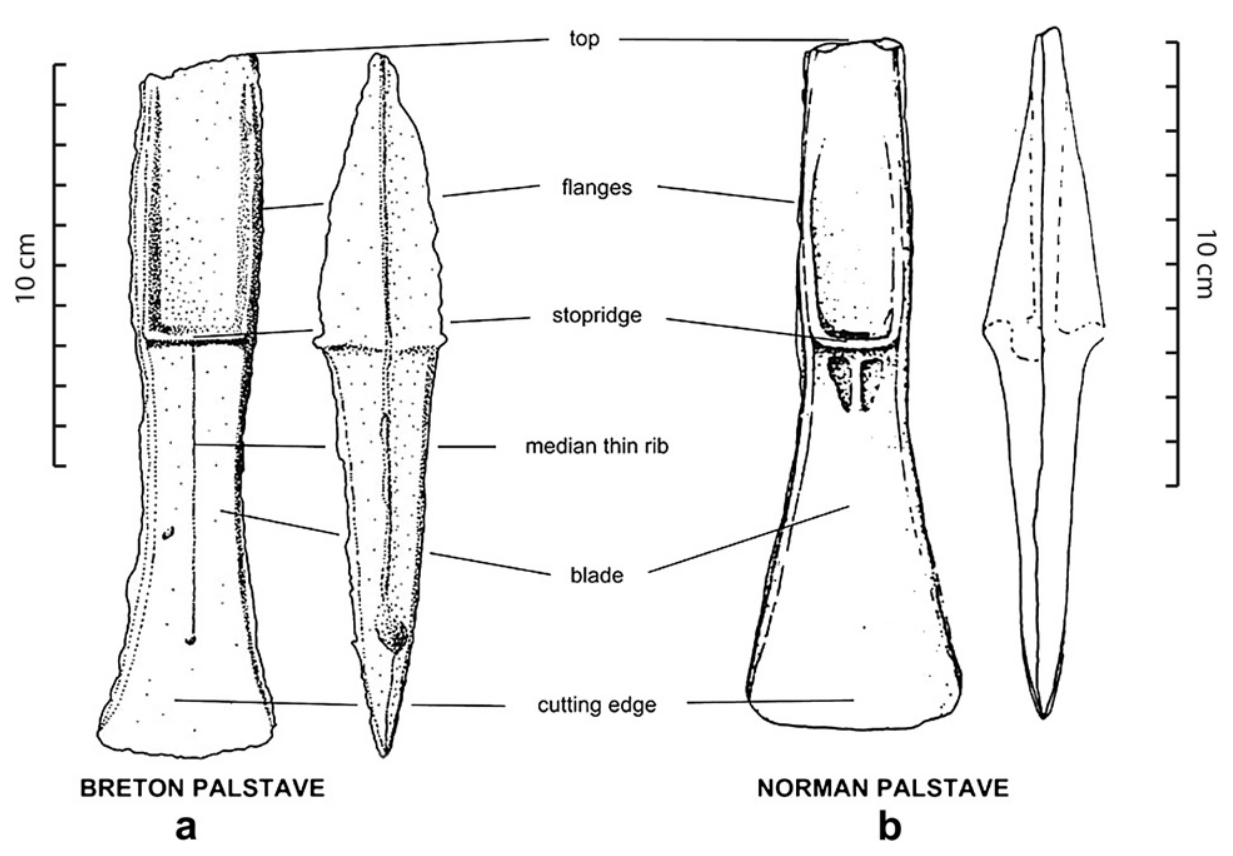

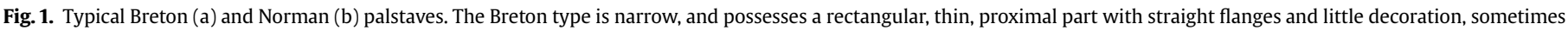

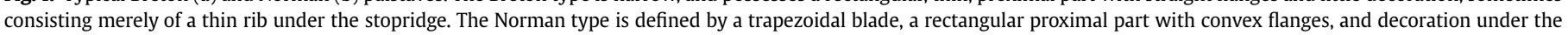
stopridge (Verney, 1989; Gabillot, 2003, illustration from Forel et al., 2009). 


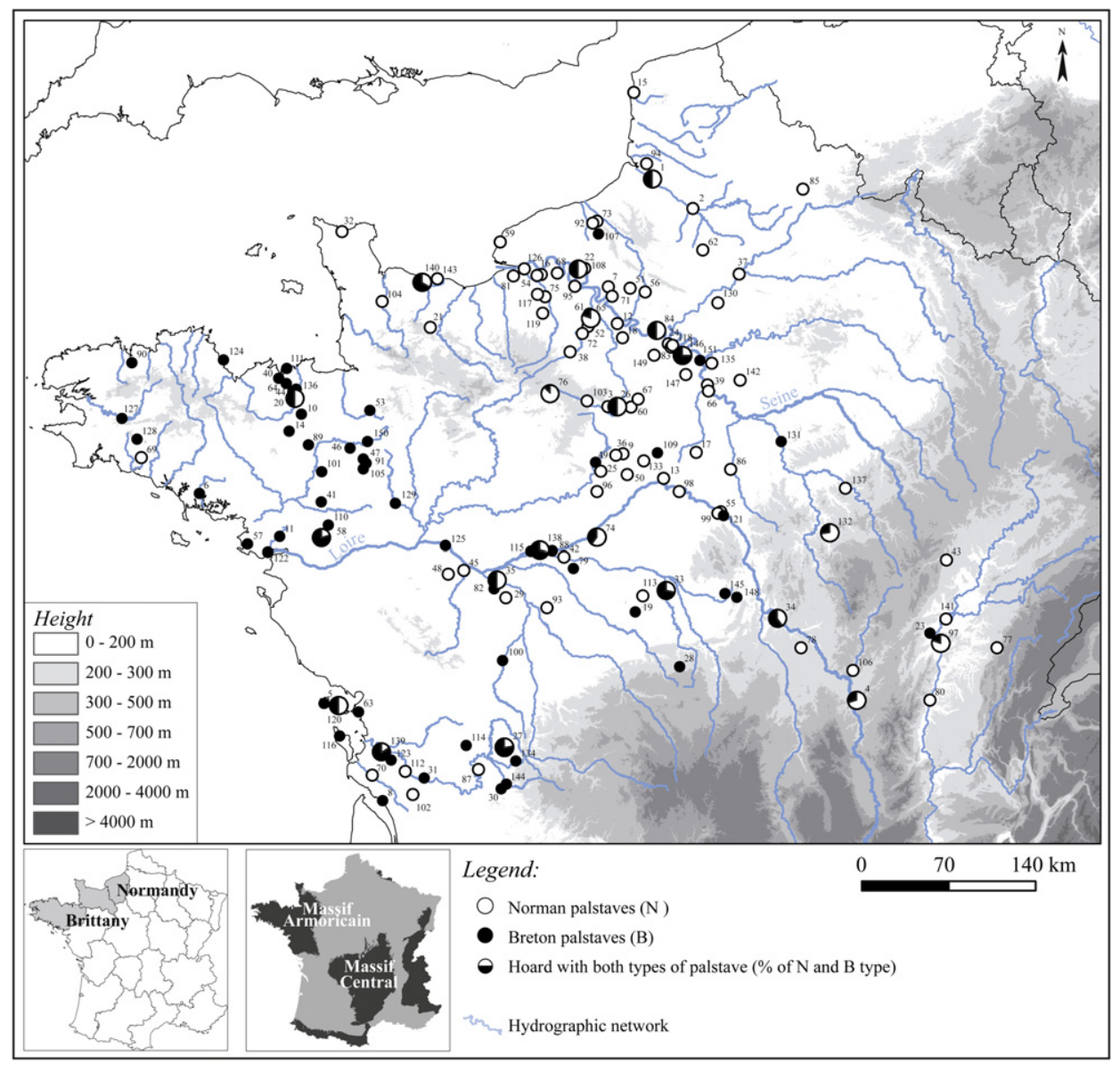

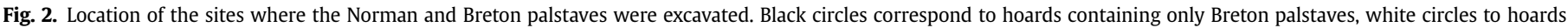

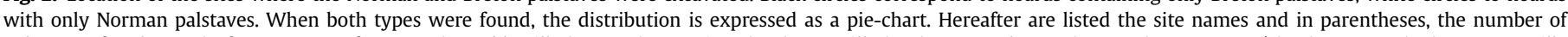

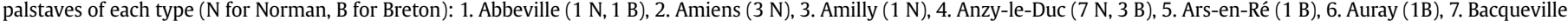

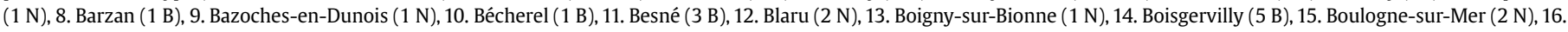

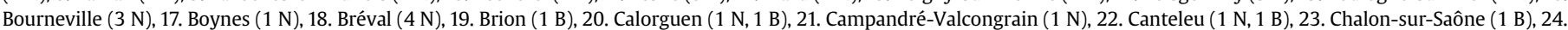

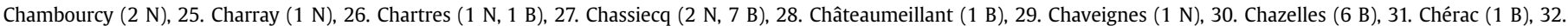

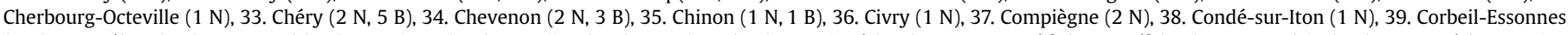

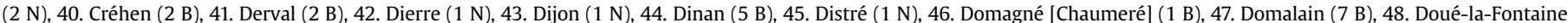

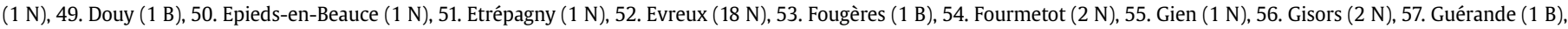

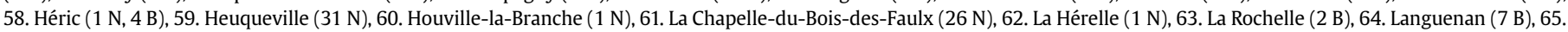

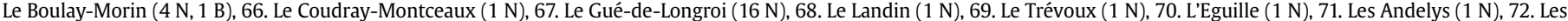

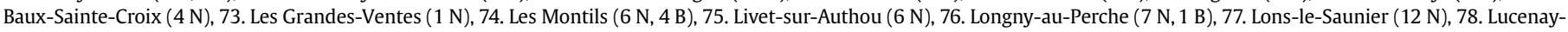

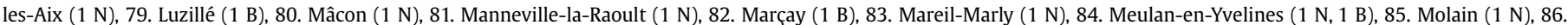

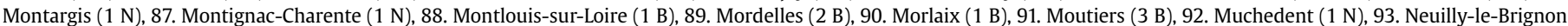

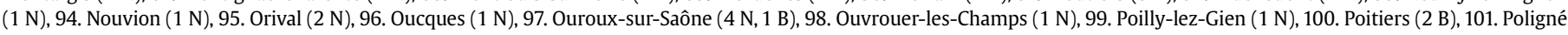

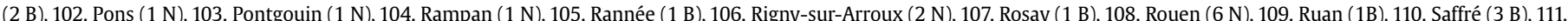

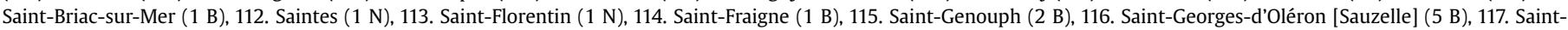

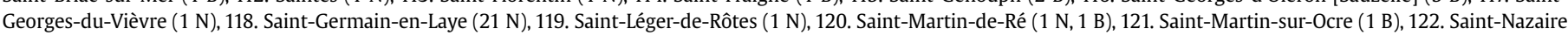

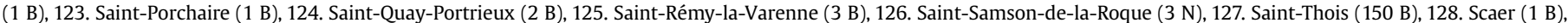

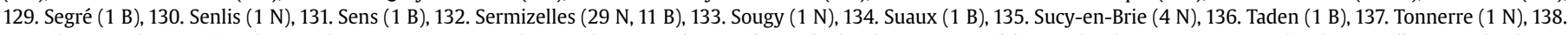

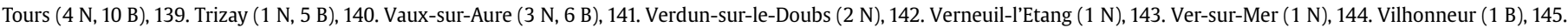
Villabon (2 B), 146. Ville-d'Avray (1 N, 3 B), 147. Villejust (1 N), 148. Villequiers (1 B), 149. Villiers-Saint-Frédéric (1 N), 150. Vitré (1 B), 151 . Vitry-sur-Seine (1 B).

considered as consumers (passive). The artifacts were discovered fortuitously throughout the 19th and 20th centuries, most of the time consecutively to agricultural works and country planning (bridges, roads and railway constructions, etc.). They sometimes consist of isolated findings but, more often, they are part of a set of palstaves, possibly including other objects such as weapons, jewelry, etc. The corpus consists of all specimens available in the archaeological literature in the form of drawings (Bouet-Langlois, 2009; Gabillot, 2001, 2003; Gomez, 1980; Mordant, unpublished; Ture, 1997), except for those items which were broken when found. It is noteworthy that the hoard of Saint-Thois predominates among the Breton type, as it represents 150 items out of a total of 319. Its presence obviously influences the geographical distribution of the Breton type, but macroscopic observations made by Gabillot (2001) tend to indicate that the shape disparity within this hoard is comparable (although not quantified) to that observed within the whole Breton type population. In the following, the assignment of a particular axe to the Breton group or to the Norman group used the currently accepted standard typology described in detail in Gabillot (2003), which provides a critical and exhaustive review of the available archaeological literature. Some original drawings available in the literature are probably not fully consistent because they may represent an idealized view of the artifacts. However, as a very large corpus of 629 items is considered here, it is reasonable 
to think that final uncertainties due to possible lack of precision of some original drawings will be eliminated, or at least considerably reduced.

\subsection{Morphometry}

\subsubsection{Drawing and sampling}

All inner lateral ribs, which consist in curves, were drawn using tracing paper (Fig. 3, steps $1 \& 2$ ). As mentioned before, the material available from Forel et al. (2009) was reused and supplemented by 249 new axes drawn by a new operator. The new operator was careful to use the same criteria for choosing the start and the end of the profile to draw, because this step was previously identified as a possible source of error (Forel et al., 2009). The good agreement between drawings of the inner lateral ribs produced by each operator was first checked on a training set of 30 palstaves before completing the corpus. The drawings were scanned at $300 \mathrm{dpi}$ and saved in TIF format (Fig. 3, step 3). Coordinates of open outlines were extracted from the TIF image using a home-made script written for MATLAB ${ }^{\circledR}$ (Fig. 3, step 4). Note that its analog can be found for the free R software (http://www.r-project.org) as the set of similar functions described in Claude (2008). Two hundred equally spaced points were sampled along the chord linking the starting and ending points ( $X$-values), and the $Y$-values were evaluated perpendicularly to these positions. Baseline registration was then operated by sending the start and the end of the profiles to the respective coordinates $(-1,0)$ and $(1,0)$ (Bookstein, 1991; cf. Fig. 3, step 5). This method rotates, translates and scales all profiles, so that the coordinates are no longer dependent on size, position or orientation.

\subsubsection{Regressing and extracting coefficients}

Profiles were regressed using Legendre orthogonal polynomials (see Rohlf, 1990 for fundamentals, and Rhode et al., 2001 for an application). More details about properties of this polynomial family can be found in the Appendix section. A script was developed for the R software, using the orthopolynom R package, which contains a set of functions (e.g. legendre.polynomials()) allowing regression to be easily computed. As with classical polynomials, coefficients are used as shape variables (Fig. 3, step 6). The higher the degree of polynomials is, the more precise is the reconstruction of the outline. The adjusted- $R^{2}$ is used to quantify the quality of reconstruction:

$R_{\mathrm{adj}}^{2}=1-\left(1-R^{2}\right)\left(\frac{n-1}{n-p}\right)$

where $n$ is the number of observations, $p$ the degree of the polynomials.

\subsubsection{Distance to the mean shape (centroid)}

Each individual, $i$, is defined by a vector, $\alpha_{i}$, containing the estimated values of coefficients, $\widehat{\alpha}_{i, k}$ ( $k$ denotes the degree of the monomials from 0 to $p$ ):
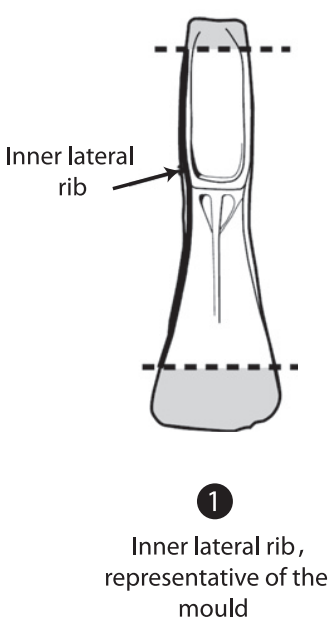
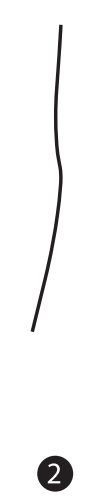

Drawing on tracing paper
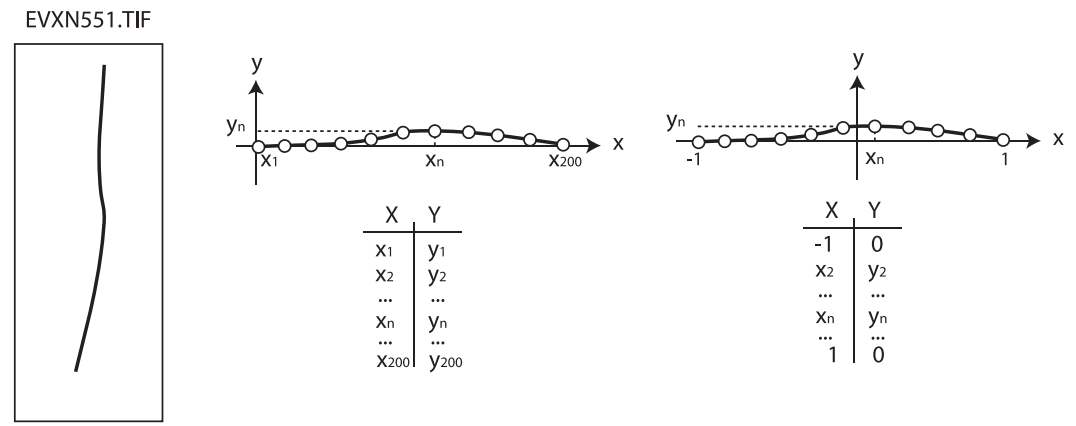

3

Scanning at $300 \mathrm{dpi}$

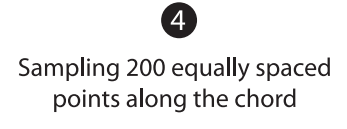

Baseline registration: First point at $(-1,0)$, last point at $(1,0)$
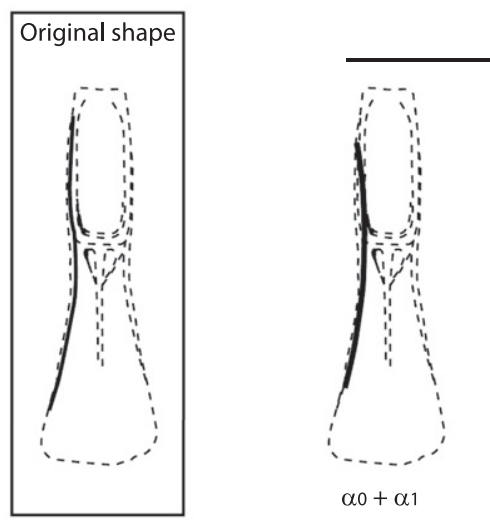

Increasing reconstruction
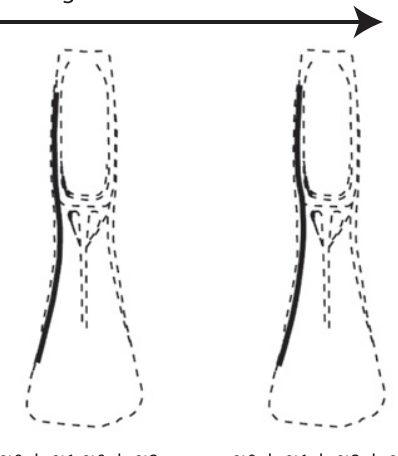

$\alpha_{0}+\alpha_{1}+\alpha_{2}+\alpha_{3}$

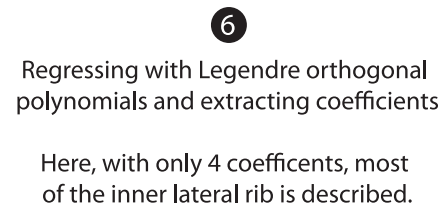

of the inner lateral rib is described.

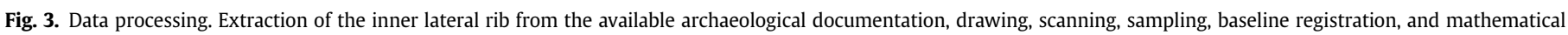
treatment. 


$$
\alpha_{i}=\left(\widehat{\alpha}_{i, 0}, \widehat{\alpha}_{i, 1}, \widehat{\alpha}_{i, 2}, \ldots, \widehat{\alpha}_{i, p}\right)^{T} \text {, }
$$

for a $p$ th-order polynomials, where $T$ denotes the transpose of the matrix. The mean group vector of each group (i.e. Breton or Norman), which represents the centroid or mean shape, is defined by $\boldsymbol{\mu}=\left(\widehat{\mu}_{0}, \widehat{\mu}_{1}, \widehat{\mu}_{2}, \ldots, \widehat{\mu}_{p}\right)^{T}$, where $\widehat{\mu}_{k}$ is the estimated mean of all $\widehat{\alpha}_{i, k}$. Then, the distance of each specimen from the centroid of its group can be evaluated using as metric the squared Mahalanobis distance, $D_{i}^{2}$ :

$D_{i}^{2}=\left(\boldsymbol{\alpha}_{i}-\boldsymbol{\mu}\right)^{T} \boldsymbol{\Sigma}^{-1}\left(\boldsymbol{\alpha}_{i}-\boldsymbol{\mu}\right)$

where $\Sigma^{-1}$ denotes the inverse of the sample covariance matrix of the typological group considered. This distance is here better adapted than the Euclidean distance because it standardizes the coefficients. Interestingly, if $\alpha$ follows a multivariate normal distribution, $D_{i}^{2}$ follows a chi-squared distribution at $p+1$ degrees of freedom (Baxter, 2003). With the R software, the Mahalanobis distance is computed using the mahalanobis() function of the stats package. Unfortunately, for each group, the presence of several outliers affects both the sample covariance matrix, $\boldsymbol{\Sigma}$, and the position of the centroid, $\mu$ (Atkinson and Mulira, 1993). That is why squared robust distances, $R D_{i}^{2}$, are frequently computed using highbreakdown robust multivariate location $(\boldsymbol{t})$ and scale estimator $(\boldsymbol{S})$ in place of $\mu$ and $\Sigma$, respectively:

$R D_{i}^{2}=\left(\boldsymbol{\alpha}_{i}-\boldsymbol{t}\right)^{T} \boldsymbol{S}^{-1}\left(\boldsymbol{\alpha}_{i}-\boldsymbol{t}\right)$

Many algorithms have been developed to assess $R D_{i}^{2}$. One of them exploits the minimum covariance determinant (MCD) to estimate the $\boldsymbol{t}$ and $\boldsymbol{S}$ matrices. It has been proved to be efficient and is widely used (e.g. Alameddine et al., 2010). Functions such as CovMcd()and getDistance() are available in the rrcov package for $\mathrm{R}$. More details about the technical calculation procedure can be found in Rousseeuw and Driessen (1999) and Alameddine et al. (2010). In order to test the validity of such an approach in our case, both classical Mahalanobis and robust distances were computed and compared. To summarize, the higher $D_{i}^{2}$ or $R D_{i}^{2}$ are, the farther the blades are from the centroids (mean shapes) of their group. On this basis, both Breton and Norman palstaves were divided into two sub-groups: $(i)$ those which can be considered as reasonably conforming to the mean shape, namely "congruent" palstaves, and (ii) those which are far enough from the mean shape to be considered as "non-congruent", although their overall characteristics identify them as either Norman or Breton.

\subsubsection{Mapping palstave density}

The spatial distribution of the two types of palstaves (Breton and Norman) was achieved using Gaussian kernel functions for bivariate data, a popular method for visualizing geographical distribution(e.g. Cusimano et al., 2010). Kernel density estimation produces interpolated maps which are invaluable for estimating values over a large region from which only samples have been taken. The degree of density estimate smoothing is controlled by bandwidths: large bandwidths produce over-smoothing which can mask some local features, whereas small bandwidths may create roughness in the estimates (see Baxter et al., 1997 for a review on the method and its potential in archaeology). As a first step, tools based on cross validation (functions available in the ks package for $\mathrm{R}$ ) were used to produce theoretical optimum bandwidths (Wand and Jones, 1994). As a second step, an empirical approach selected bandwidths of $50 \mathrm{~km}$ for $X$ and $Y$, which is slightly higher than values provided by the cross validation method $(35-40 \mathrm{~km})$. Such values were preferred as they tend to over-smooth the density estimate, and substantially reduce the chance of over-interpretation (Stevens et al., 2009).

\subsubsection{Cluster detection}

First, an approach based on a dual kernel density estimate (socalled kernel density ratio) was applied to our set of data to examine visually the geographical structure in terms of under- or over-representation of non-congruent palstaves (see Siqueira et al., 2004 for details and an application in medicine). In other words, the purpose was to see if the ratio of densities of congruent/noncongruent blades is the same everywhere or not. Dual kernel was computed by dividing the density estimations of congruent palstaves by those of non-congruent palstaves. Although visually friendly, this procedure suffers from major drawbacks. Regions far from the discovery of non-congruent palstaves lead to computation of anomalously high congruent/non-congruent ratios, so that only the regions with an appreciable number of palstaves can be taken into account in the analysis. Moreover, census data are ignored and the statistical significance of the obtained ratios in relation to random fluctuations cannot be evaluated under a Bernoulli probability distribution.

To palliate this weakness, the procedure was supplemented by the use of scan statistics to identify statistically significant areas with high or low proportions of non-congruent palstaves. This step was performed using SaTScan v9.1 (http://www.satscan.org/; Kulldorff et al., 1998), software very widely used in the health sciences (e.g. Green et al., 2003; Beroll et al., 2007). Basically, the space is progressively scanned using ellipses of gradually expanding size, moving from one finding location to another, in which non-congruent and congruent axes are counted. For each scanning window center and size, the congruent $v s$. non-congruent distribution is tested against the null hypothesis, which corresponds to spatial randomness, meaning that the proportion of non-congruent palstaves is the same everywhere, inside and outside the ellipse. The window with the maximum likelihood is the most likely cluster. Secondary clusters with lower likelihood may also be detected (see Kulldorff and Nagarwalla, 1995; and the operating manual provided with the SaTScan software for details about $p$-value calculations). Scans were operated for areas with high or low rates of cases (a case is here a non-congruent palstave), in other words to identify regions where proportions of non-congruent palstaves are significantly too high or too low to be compatible with spatial randomness.

\section{Results and discussion}

\subsection{Choice of the number of coefficients necessary to describe the palstaves}

The full set of palstaves ( $n=629$ ) was sequentially regressed using orthogonal polynomials with $p$, the order of polynomials, increasing from 1 to 10 . It appears that the adjusted- $R^{2}$ quickly increased to reach values close, on average, to 0.95 from $p=3$ (Fig. 3, step 6; Fig. 4). In other words, about $95 \%$ of the variation of the inner lateral rib is described only by four numbers: the first three coefficients plus the constant. From that point, adjusted- $R^{2}$ slowly increases to tend asymptotically toward 1 (Fig. 4). The high goodness of fit obtained with only a cubic polynomial regression is due to the simplicity of the profiles with, at worst, two local maxima/minima. Increasing the order of polynomials (i.e. by taking $p>3$ ) will slightly improve the goodness of fit, but may also have a deleterious effect on the calculation of the distance of each individual from the group centroid because each coefficient $\alpha_{k}$ acts in a same way due to normalization by its variance. Mixing at equal weight high-order polynomial coefficients (which explain little of the variance) with the first four polynomial coefficients (which explain almost $95 \%$ of the total variance) is definitely not a good choice. As a result, the following steps were performed using only 


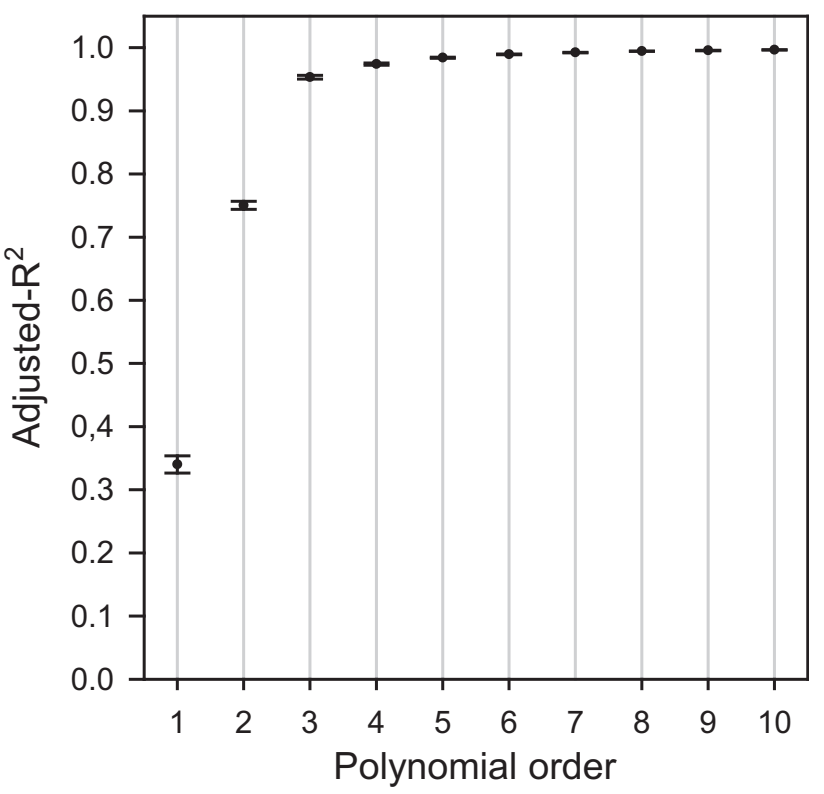

Fig. 4. Average adjusted- $R^{2} v s$. the order of orthogonal polynomial model used for treating the 629 palstaves. Error bars represent the $95 \%$ confidence interval of the mean value.

the first 4 coefficients obtained by Legendre orthogonal polynomial regression (i.e. considering a third-order regression).

\subsection{Discriminating congruent and non-congruent palstaves}

Mahalanobis and robust distances, which separate the specimens from the mean shape of their group, were computed separately for Breton and for Norman types. If the coefficients follow a multivariate normal distribution, $D_{i}^{2}$ and $R D_{i}^{2}$ are supposed to follow chi-squared distributions at $p+1$ degrees of freedom (here $p=3$, see above). The quality of the adjustment to the expected multivariate normal distribution is represented in the form of sample quantile $v s$. theoretical $\left(\sim \chi_{4}^{2}\right)$ quantile diagrams. In the Mahalanobis plots (Fig. 5a,b), specimens close to the centroid match well the theoretical $\chi_{4}^{2}$ distribution (although they plot sometimes slightly below the $y=x$ line), suggesting that polynomial coefficients, at least for these individuals, roughly follow a multivariate normal distribution. However, from a certain point, sample values drastically diverge from theoretical quantiles, indicating the occurrence of outliers, which may have parasitized by their simple presence the calculation of the covariance matrix $(\boldsymbol{\Sigma})$ and of the centroid location $(\boldsymbol{\mu})$. When computing robust distances in place of Mahalanobis distances, the situation becomes clearer (Fig. 6a,b). The specimens close to the centroid now almost perfectly fit the theoretical $\chi_{4}^{2}$ - based distances, while the point at which divergence begins becomes much more clearly identifiable, especially for the Breton palstaves (see Fig. 5b vs Fig. 6b). These procedures, based on assumed multivariate normal distribution of estimates, are often applied for outlier detection by experimental scientists. For this purpose, atypical observations are generally considered to result from measurement or transcription errors, or may even derive from exceptional events, which are, by definition, not supposed to occur frequently. By convention, any point which has a $D_{i}^{2}$ (or $R D_{i}^{2}$ depending on calculation strategies) exceeding $\chi_{d f=v, 0.975}^{2}$, is considered as atypical. Such a threshold makes the whole procedure highly conservative (i.e. only a few samples are rejected). A straightforward application of this convention is not appropriate here, because there may be a high proportion of non-congruent palstaves in both Norman and Breton populations. That is why thresholds used to separate both groups into congruent and noncongruent sub-groups were set at the distance where robust distance values start to diverge from theoretical expectations. Such thresholds are materialized in Fig. 6a,b by horizontal lines at $R D_{i}^{2}>5.4$ for the Norman and $R D_{i}^{2}>6.8$ for the Breton palstaves. These cut-offs identify 77 non-congruent palstaves out of a total of 310 (24.8\%) for the Norman type (Fig. 6a) and 53 non-congruent palstaves out of a total of $319(16.6 \%)$ for the Breton type (Fig. 6b). The drawings of specimens depicted in Fig. 6a,b help to assess where the congruent palstaves stand in contrast to the noncongruent ones.

\subsection{Mapping shape distribution for the two groups}

\subsubsection{The Norman group}

Fig. 7a represents the kernel density interpolation for the Norman group. The highest density is observed between Paris and the mouth of the Seine and lies along the Seine, although a minor site is also recognized in Burgundy. Under the null hypothesis that the proportion of non-congruent axes is spatially independent, the density ratio congruent/non-congruent should randomly fluctuate around 3 (233 congruent specimens/77 non-congruent specimens $=3.03$ ), and should not exhibit any spatial structure. The reality is quite different as the dual kernel produces a clear pattern (Fig. 7b). An area (ellipse 1), perfectly matching the highest
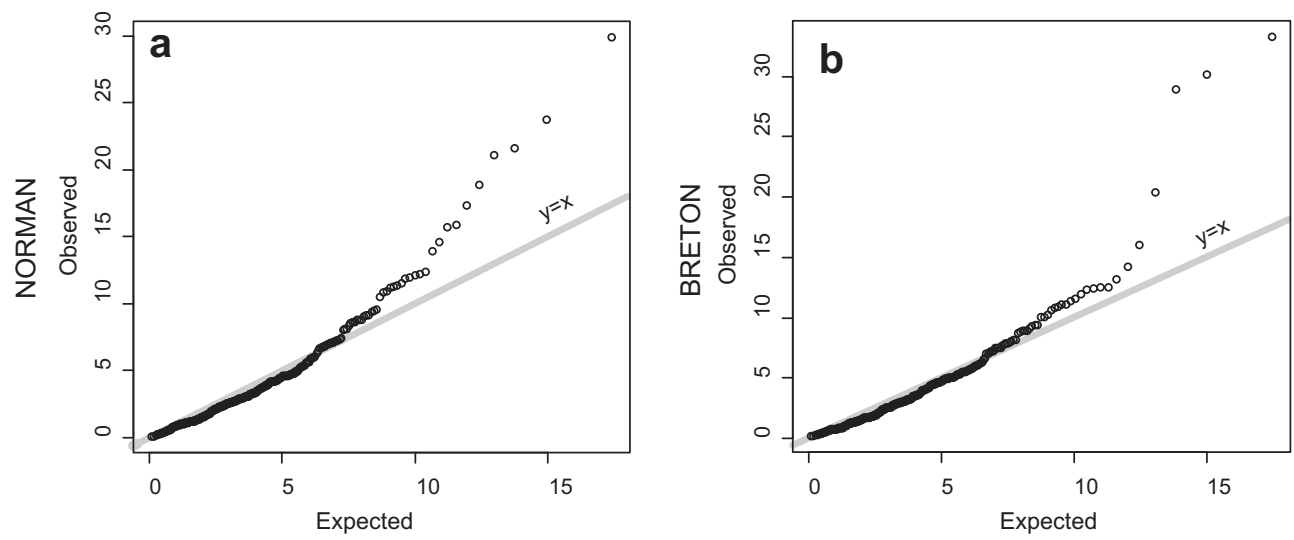

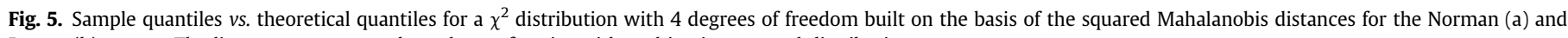
Breton (b) groups. The line $y=x$ corresponds to the conformity with multivariate normal distribution. 

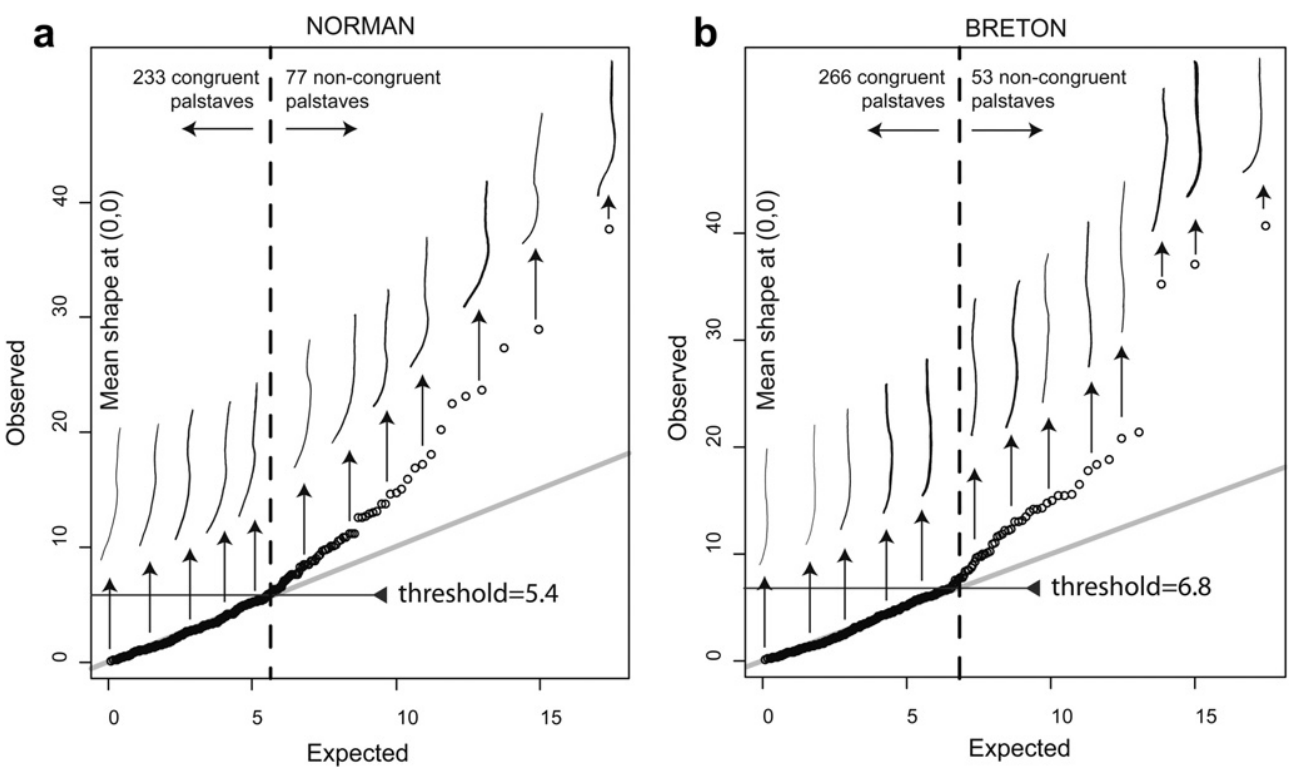

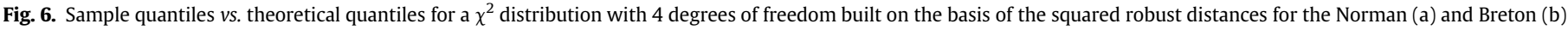

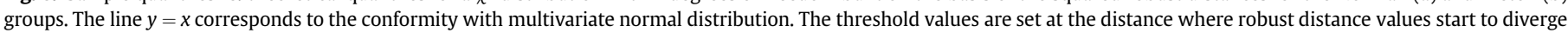

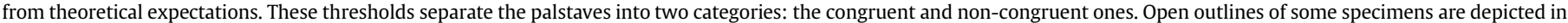
order to make clearer the progressive divergence from the mean shape.

densities of discovery (Fig. 7a), is clearly identified by scan statistics as presenting a significantly low rate of non-congruent pasltaves: out of a total of 148 palstaves, only 14 are non-congruent, whereas 36.8 specimens would be expected. Such a distribution is too unbalanced to result from a Bernoulli probability model $\left(p=10^{-5}\right)$. Another area covering part of Burgundy and the northern Massif Central (ellipse 2) is statistically recognized as exhibiting an anomalously high rate of non-congruent palstaves $(p=0.027)$ : out
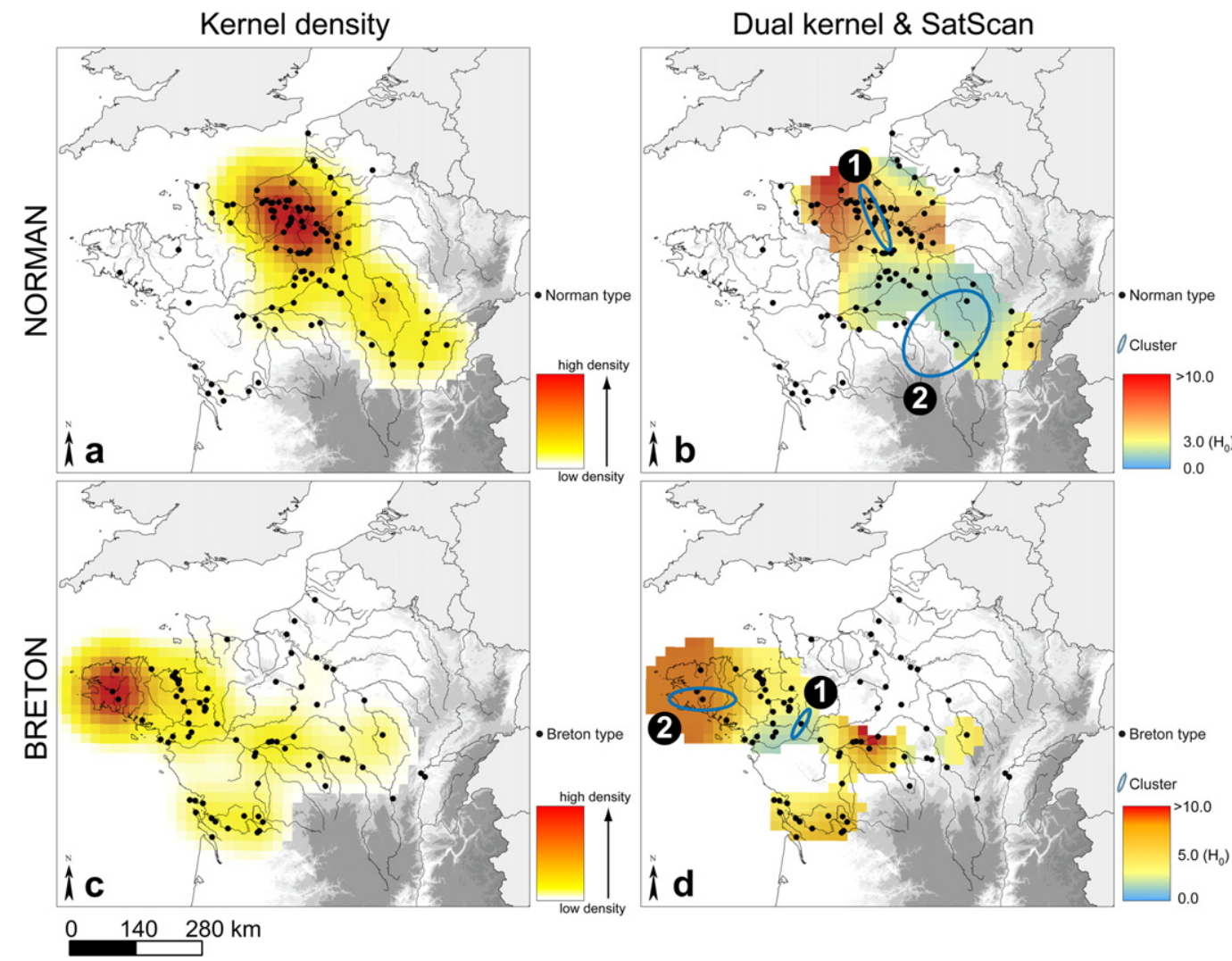

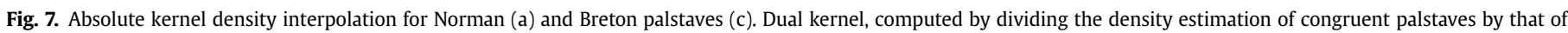

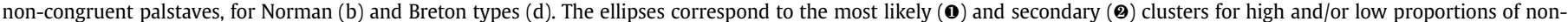

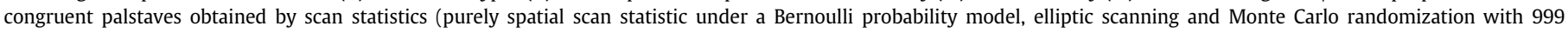
permutations). 
of a total of 89,38 are non-congruent, whereas 22.1 would be expected. The null hypothesis must therefore be rejected for the Norman group.

\subsubsection{The Breton group}

Fig. 7c represents the kernel density interpolation for palstaves belonging to the Breton type. The extreme east of Brittany is a hot spot, but such a high-density position is governed by the presence of the Saint Thois hoard. Under the null hypothesis, the dual kernel is supposed to oscillate randomly around 5 (266 congruent items/ 53 non-congruent items $=5.02$ ). The moderate spatial structure observed is in part confirmed by scan statistics (Fig. 7d). The most likely cluster (ellipse 1, located close to the low Loire valley) shows a significantly high proportion of non-congruent palstaves $(p=0.048)$ : where the 5 axes within the ellipse are all noncongruent, while only 0.83 items would be expected. A secondary cluster is identified in the extreme east of Brittany (ellipse 2, which encompasses the Saint Thois hoard), with 16 non-congruent palstaves out of a total of 159 , while 26.42 would be expected. However, it does not appear statistically significant since its $p$-value is 0.702 . The situation for the Breton axes seems therefore to be much less clear than for the Norman ones.

\section{Archaeological interpretation}

\subsection{Inferences for Norman-type production}

First of all, the highest density of Norman palstave discovery does not precisely match the current eponymous Normandy administrative region, but rather lies along the middle and low Seine valley. One simple scenario might explain the areas where high and low proportions of non-congruent palstaves are observed (Fig. 7b). Metalworkers produced the entire set of socalled Norman palstaves along the Seine, but they preferentially exported the models which differed the most from the mean standard shape, so that nowadays, there is a low proportion of non-congruent specimens inside the region of production, and a higher proportion outside. Although theoretically acceptable, this scheme is not likely; first, because it is not always easy to distinguish the non-congruent specimens with the naked eye, even for such skilled metalworkers, and second because that would imply a stricter management of exchanges than could plausibly have existed at that time. A more likely explanation is that the majority of Norman palstaves were manufactured according to rules that metalworkers had to follow, in the low Seine valley where the type was probably invented. There would have been little incentive to develop new shapes, or variations around the original model. Such a scenario explains why noncongruent palstaves are proportionally less abundant in the low Seine valley. That would imply control over the production, but the way in which this control was exerted is not clear. One can invoke control by the elites, the control of only a few metalworkers over a large production, or multiple producers following a very strict technological style (i.e. control through socially accepted standards); these hypotheses are not mutually exclusive. Some of the palstaves produced in the middle and low Seine valley, including both congruent and non-congruent blades, were exported to neighboring communities, who were familiar with the original Norman type. These communities may also have produced their own blades following the Norman model, but their copies exhibited greater shape disparity, so that non-congruent palstaves are proportionally more abundant than in the low Seine valley. These 'Norman-like' palstaves are found in greater proportion in Burgundy and in the northern Massif Central. Some of these copies may also have been exported elsewhere.

\subsection{Inferences for Breton-type production}

The highest density of Breton palstave discovery matches the Brittany peninsula, even when the Saint Thois hoard, with its 150 specimens, which overwhelms the analysis, is removed (not shown here). One area with a high proportion of non-congruent palstaves is observed, but it concerns too limited a subset of the corpus (only 5 items) to be of real archaeological relevance. Additional tests (not shown here) were performed by removing the hoard of Saint Thois, but no spatial structure could be statistically identified, perhaps because of the drastic downsizing. Several scenarios can be invoked to explain the relatively homogeneous spatial distribution of congruent vs non-congruent Breton palstaves: (i) most of the production, including congruent and non-congruent palstaves, took place in Brittany and was partly exported to neighboring regions indistinctly, (ii) palstaves were produced in Brittany, but copies were made elsewhere; however, these copies matched the original model so well that they are not distinguishable by spatial statistics, or (iii) intense circulation of artifacts masks the initial distribution. It is noteworthy that any inferences made here are drawn from a corpus which can be biased with respect to the original distribution. In the current state of knowledge, it is impossible to favor either of these hypotheses using this corpus.

\subsection{Exchanges of raw material and formed artifacts}

In the low Seine valley, metal resources are lacking, so that raw material used by metalworkers had necessarily to be acquired elsewhere. England, the Alps and southern France, where prehistoric mines have been discovered and studied (Barge, 1997; Ambert et al., 2002), are classically evoked as the main providers of copper and tin at that time (Routhier, 1999). Abundant mineral resources from the surrounding French crystalline massifs may also have been used. In Brittany, mineral resources are abundant although there is currently no archaeological evidence of their exploitation. In the Vosges massif, the recent analysis of metallic pollution archived in a peat bog reported a geochemical anomaly around 1500 cal. BP, which might possibly be related to atmospheric emissions consecutive to local mining and smelting (Forel et al., 2010). The presence of mining during the Bronze Age has been demonstrated in the Morvan (northern Massif Central) using the same methodology that has been applied to several peat cores (Monna et al., 2004; Jouffroy-Bapicot et al., 2008), in other words in areas formerly considered by archaeologists as passive with respect to metal production and consumption at that time. The accessibility of abundant local raw material in the northern Central Massif may have been an asset for the development of local metallurgy, which took as models the Norman (and perhaps the Breton) palstaves. A major result of the present study is that, at least for the Norman type, a clear spatial structure in terms of high or low proportions of non-congruent palstaves can now be seen. This necessarily implies that exportation/importation exchanges were limited for this type, otherwise the spatial structure observed would have vanished due to the homogenization consecutive to intense circulation.

\section{Conclusions}

The difference between the traditional approach made by archaeologists dealing with typology and morphometrics is that shape disparity within a type can be only roughly assessed by the naked eye (especially when several hundreds of specimens are considered), while it can be precisely quantified by morphometrics. That constitutes a valuable advance, which complements traditional typology. Accompanied by spatial analysis, the information contained in artifact shape disparity can be a precious tool to 
identify artifact production areas and exchange networks. The procedure is based on objective measurements and hypothesis testing, making it reliable, reproducible and capable of being updated when new discoveries are made. However, it requires the discrimination of congruent vs non-congruent objects, which is not as straightforward as in other studies (e.g. epidemics, where the status - sick/not sick - can most of the time be determined unambiguously). In the case of archaeological materials, an appropriate method to determine a threshold has to be found. The close examination of the robust distances from the centroid provides efficient guidelines here. If the structure of the data is clear enough, the results of the spatial analysis will be highly robust, as is the case here for the Norman type. In all cases, a large corpus is desirable.

More specifically for the Bronze Age palstaves, it is demonstrated that the low Seine valley is the place where most of the Norman-type palstaves were produced, with low shape variation. This tends to imply a strict control of production in this area. The artifacts were exported from there, but other minor centers, in Burgundy and in the northern Massif Central, probably copied them, but with less stability around the standard shape. If such a spatial structure can still be seen nowadays, it must mean that the intense exchanges leading to geographical homogeneity did not occur. The situation is less clear for the Breton palstaves, which exhibit almost homogeneous spatial distribution with respect to congruent and non-congruent sub-group proportions. Therefore, in this case, no clear archaeological inferences can reasonably be drawn for the Breton palstaves, for which several scenarios are still envisageable.

\section{Acknowledgments}

We are grateful to the anonymous reviewers whose judicious comments improved the manuscript.

\section{Appendix A}

\section{Orthogonal polynomials}

Considering the simplicity of the profiles, a straightforward procedure would consist in regressing the curves by classical polynomial functions (Rohlf, 1990). With $n$ points $\left(X_{j}, Y_{j}\right), j=1$, $2, \ldots, n$, where $X$ is a predictor variable (the abscises) and $Y$ is a response (the ordinates), we obtain :

$Y=\sum_{i=0}^{p} \beta_{i} X^{i}+\varepsilon$

where $\beta_{i}$ represent the coefficients sought and $\varepsilon$ the error term. However with classical polynomials, multicolinearity of predictors $\left(1, X, X^{2}, X^{3}, \ldots, X^{p}\right)$ occurs, especially at a high degree, even when the $X$ are centered or, better, rescaled in $[-0.5,0.5]$, as recommended by numerous textbooks (e.g. Marques de Sá, 2007). The covariance matrix tends to be ill-conditioned, leading to problems in fitting by least squares. As a consequence, the $\widehat{\beta}_{i}$ coefficients estimated may appear to be somewhat unstable (small changes in $Y$ may lead to relatively large changes in $\widehat{\beta}_{i}$ ) and they are correlated. Adding another term $\beta_{i+1} X^{i+1}$ induces changes in the estimates of all coefficients. Substantial benefit can be found with orthogonal polynomials because they produce coefficients which are not correlated (Smyth, 1998). The basis composed by the predictors is orthogonal, leading to minimized approximation and round-off errors (Draper and Smith, 1998):

$$
Y=\sum_{i=0}^{p} \alpha_{i} \varphi_{i}(X)+\varepsilon
$$

where $\alpha_{i}$ represent the coefficients sought, and $\varphi_{i}(X)$ the orthogonal polynomials associated to the scalar product:

$(P \mid Q)=\int_{-1}^{1} P(x) Q(x) d x$

The sequence of Legendre polynomials can be obtained by recurrence, $\varphi_{0}(x)=1, \varphi_{1}(x)=x$, and then by the Bonnet's recursion formula:

$(n+1) \varphi_{n+1}(x)=(2 n+1) x \varphi_{n}(x)-n \varphi_{n-1}(x)$ They can then be normalized by replacing $\varphi_{i}(x)$ by $\frac{\varphi_{i}(x)}{\left\|\varphi_{i}(x)\right\|}$ where
$\left\|\varphi_{i}(x)\right\|=\sqrt{\left(\varphi_{i}(x) \mid \varphi_{i}(x)\right)}$

Estimated $\widehat{\alpha}_{i}$ coefficients, calculated using a least squares procedure, are uncorrelated when $X$ is uniformly distributed over $[-1,1]$. Unlike classical polynomials, these coefficients have no meaning when adjusted to a known physical law, but this is not a drawback here because the purpose is only to describe shapes. On the other hand, higher order polynomials can be computed without modifying the lower order coefficients. This simplifies the determination of the degree at which a suitable fitting equation is found.

\section{References}

Alameddine, I., Kenney, M.A., Gosnell, R.J., Reckhow, K.H., 2010. Robust multivariate outlier detection methods for environmental data. Journal of Environmental Engineering-ASCE 136, 1299-1304.

Ambert, P., Coularou, J., Cert, C., Guendon, J.-L., Bourgarit, D., Mille, B., Dainat, D., Houlès, N., Baumes, B., 2002. Le plus vieil établissement de métallurgistes de France (IIle millénaire av. J.-C.): Péret (Hérault). Comptes Rendus Palevol 1, 67-74.

Atkinson, A.C., Mulira, H.M., 1993. The stalactite plot for the detection of multivariate outliers. Statistics and Computing 3, 27-35.

Barge, H., 1997. L'installation métallurgique préhistorique de la cabane des Clausis à Saint-Véran (Hautes-Alpes). Archéologie en Languedoc 21, 99-110.

Baxter, M.J., Beardah, C.C., Wright, R.V.S., 1997. Some archaeological applications of kernel density estimates. Journal of Archaeological Science 24, 347-354.

Baxter, M., 2003. Statistics in Archaeology. Arnold Applications of statistics, London. $291 \mathrm{p}$.

Beroll, H., Berke, O., Wilson, J., Barker, I.K., 2007. Investigating the spatial risk distribution of West Nile virus disease in birds and humans in southern Ontario from 2002 to 2005. Population Health Metrics 5 (3). http://dx.doi.org/10.1186/ 1478-7954-5-3.

Bookstein, F.L., 1991. Morphometric Tools for Landmark Data: Geometry and Biology. Cambridge University Press. 435 p.

Bouet-Langlois, B., 2009. Nouveaux dépôts de haches à talon en Ile-de-France. Observations macroscopiques, techniques et typologiques. Revue Archéologique d'Ile-de-France 2, 65-88.

Briard, J., 1965. Les dépôts bretons et l'âge du Bronze atlantique. Travaux du laboratoire d'anthropologie de la Faculté des Sciences, Rennes. 352 p.

Briard, J., Verron, G., 1976. Typologie des objets de l'âge du Bronze en France, III: Haches (1), IV: Haches (2), herminettes. Société Préhistorique Française, Commission du Bronze, Paris.

Briard, J., Bigot, B., 1989. Le bronze atlantique: de Tréboul aux haches à talon en Armorique in: Actes du 113ème Congrès des Sociétés Savantes, La culture des tumulus et la dynamique du Bronze moyen en Europe occidentale. Editions du Comité des Travaux Historiques et Scientifiques, Paris, 523-536 pp.

Claude, J., 2008. Morphometrics with R. Springer. 318 p.

Cusimano, M., Marshall, S., Rinner, C., Jiang, D., Chipman, M., 2010. Patterns of urban violent injury: a spatio-temporal analysis. PLoS ONE 5 (1), e8669. http:// dx.doi.org/10.1371/journal.pone.0008669.

Dommergues, J.L., Dommergues, C.H., Meister, C., 2006. Exploration of the Oxynoticeratidae ornemental morphospace using the discrete cosine transform (DCT) to analyze rib patterns. Paleobiology 32 (4), 628-651.

Dommergues, C.H., Dommergues, J.L., Verrecchia, E.P., 2007. The discrete cosine transform, a Fourier-related method for morphometric analysis of open contours. Mathematical Geology 33 (8), 749-763.

Draper, N.R., Smith, H., 1998. Applied Regression Analysis, third ed. John Wiley \& Sons, $736 \mathrm{pp}$.

Forel, B., Gabillot, M., Monna, F., Forel, S., Dommergues, C.H., Gerber, S., Petit, C., Mordant, C., Chateau, C., 2009. Morphometry of Middle Bronze Age palstaves by discrete cosine transform. Journal of Archaeological Science 36, 721-729. 
Forel, B., Monna, F., Petit, C., Bruguier, O., Losno, R., Fluck, P., Begeot, C., Richard, H., Bichet, V., Chateau, C., 2010. Historical mining and smelting in the Vosges Mountains (France) recorded in two ombrotrophic peat bogs. Journal of Geochemical Exploration 107, 9-20.

Gabillot, M., 2001. Le dépôt de haches à talon de la fin du Bronze moyen découvert à Saint-Thois (Finistère). Revue Archéologique de l'Ouest 18, 27-44.

Gabillot, M., 2003. Dépôts et production métallique du Bronze moyen en France nord-occidentale. In: British Archaeological Reports. International Series, vol. 1174. $471 \mathrm{p}$.

Gabillot, M., 2006. Les manipulations après la fonte des objets en alliage cuivreux: caractéristique sociale, économique, culturelle? L'exemple des haches à talon du Bronze moyen du Nord-Ouest français, Normes techniques et pratiques sociales, de la simplicité des outillages pré-et protohistoriques. In: Astruc, L., Bon, F., Léa, V., Milcent, P.-Y., Philibert, S. (Eds.), Actes des XXVIe Rencontres internationales d'Archéologie et d'Histoire d'Antibes, pp. 287-296.

Gabillot, M., Forel, B., Naudin, A., Monna, F., Losno, R., Piningre, J.F., Mordant, C., 2009. Influences atlantiques dans les productions métalliques en Bourgogne et Franche-Comté au Bronze moyen, L'Isthme européen Rhin-Saône-Rhône dans la Protohistoire, Approches nouvelles en hommage à Jacques-Pierre Millotte. Besançon, 133-144.

Gomez, J., 1980. Les cultures de l'âge du Bronze dans le bassin de la Charente. Pierre Fanlac, Périgueux, 118 pp.

Green, C., Hoppa, R.D., Kue Young, T., Blanchard, J.F., 2003. Geographic analysis of diabetes prevalence in an urban area. Social Science and Medicine 57, 551-560.

Jouffroy-Bapicot, I., Pulido, M., Baron, S., Galop, D., Monna, F., Lavoie, M., Petit, C., de Beaulieu, J.-L., Richard, H., 2007. Environmental impact of early palaeometallurgy: pollen and geochemical analysis. Vegetation History and Archaeobotany 16, 251-258.

Jouffroy-Bapicot, I., Forel, B., Monna, F., Petit, C., 2008. Paléométallurgie dans le Morvan: l'apport des analyses polliniques et géochimiques. In: du CTHS (Ed.), Le peuplement de l'arc alpin, Paris, pp. 323-334.

Kulldorff, M., Nagarwalla, N., 1995. Spatial disease clusters: detection and inference. Statistics and Medicine 14 (8), 799-810.

Kulldorff, M., Rand, K., Gherman, G., Williams, G., DeFrancesco, D., 1998. SaTScan v2.1: Software for the Spatial and Space-time Scan Statistics. National Cancer Institute, Bethesda, MD.

Marques de Sá, J.P., 2007. Applied Statistics Using SPSS, STATISTICA, MATLAB and R. Springer, 505 pp.

Monna, F., Petit, C., Guillaumet, J.-P., Jouffroy-Bapicot, I., Blanchot, C., Dominik, J., Losno, R., Richard, H., Lévêque, J., Chateau, C., 2004. History and environmental impact of mining activity in Celtic Aeduan territory recorded in a peatbog (Morvan - France). Environmental Science and Technology 38 (3), 657-673.

O'Connor, B., 1980. Cross-channel Relations in the Later Bronze Age, Relations Between Britain, North-Eastern France and the Low Countries During the Later Bronze Age and the Early Iron Age, with Particular Reference to the Metalwork. In: British Series, vol. 91. British Archaeological Reports, Oxford.

Rhode, K.M., Pappas, J.L., Stoermer, E.F., 2001. Quantitative analysis of shape variation in type and modern populations of meridion (Bacillariophyceae). Journal of Phycology 37 (1), 175-183.

Rohlf, F.J., 1990. Fitting curves to outlines. In: Rohlf, F.J., Bookstein, F.L. (Eds.), Proceedings of the Michigan Morphometrics Workshop, Spec. Publ. No. 2. University of Michigan Museum of Zoology, Ann Arbor, pp. 167-177.

Rousseeuw, P.J., Driessen, K.V., 1999. A fast algorithm for the minimum covariance determinant estimator. Techtonometrics 41, 212-223.

Routhier, P., 1999. Voyage au monde du métal. In: Inventions et aventures. Belin Pour la science. $159 \mathrm{p}$.

Rowlands, M.J., 1976. The Production and Distribution of the Metalwork in the Middle Bronze Age in Southern Britain. In: British Series, vol. 31. British Archaeological Reports, Oxford.

Siqueira, J.B., Martelli, C.M.T., Maciel, I.J., Oliveira, R.M., Ribeiro, M.G., Amorim, F.P., Moreira, B.C., Cardoso, D.D.P., Souza, W.V., Andrade, A.L.S.S., 2004. Household survey of dengue infection in Central Brazil: spatial point pattern analysis and risk factors assessment. American Society of Tropical Medicine and Hygiene 71, 646-651.

Smyth, G.K., 1998. Polynomial approximation. In: Armitage, P., Colton, T. (Eds.), Encyclopedia of Biostatistics. John Wiley \& Sons, Ltd, Chichester.

Stevens, K.B., Del Río Vilas, V.J., Guitián, J., 2009. Classical sheep scrapie in Great Britain: spatial analysis and identification of environmental and farm-related risk factors. BMC Veterinary Research 5 (33), 1-12.

Ture, I., 1997. Les Dépôts de haches à talon d'Anzy-le-Duc, d'Ouroux-sur-Saône (Saône-et-Loire) et de Lons-le-Saunier (Jura), Mémoire de maîtrise. Université de Bourgogne.

Verney, A., 1989. La place des haches à talon de type normand dans l'étude du Bronze moyen en France. In: Actes du 113ème Congrès des Sociétés Savantes, La culture des tumulus et la dynamique du Bronze moyen en Europe occidentale. Editions du Comité des Travaux Historiques et Scientifiques, Paris, pp. 479-489.

Wand, M.P., Jones, M.C., 1994. Multivariate plugin bandwidth selection. Computational Statistics 9, 97-116. 